13

\title{
Сверхтонкие эпитаксиальные пленки кобальта, сформированные под графеном
}

\author{
(С) М.В. Гомоюнова ${ }^{1}$, Г.С. Гребенюк ${ }^{1}$, Д.А. Смирнов ${ }^{2,3}$, И.И. Пронин ${ }^{1,4, q}$ \\ ${ }^{1}$ Физико-технический институт им. А.Ф. Иофрфе РАН, \\ Санкт-Петербург, Россия \\ ${ }^{2}$ Санкт-Петербургский государственный университет, \\ Санкт-Петербург, Россия \\ ${ }^{3}$ Institute of Solid State Physics, Dresden University of Technology, \\ Dresden, Germany \\ ${ }^{4}$ Санкт-Петербургский национальный исследовательский университет \\ инорормационных технологий, механики и оптики, \\ Санкт-Петербург, Россия \\ ๆ E-mail: Igor.Pronin@mail.ioffe.ru
}

(Поступила в Редакцию 5 апреля 2017 г.)

Исследован процесс интеркаляции кобальта под однослойный графен, выращенный на монокристаллической пленке $\mathrm{Ni}(111)$. Эксперименты проведены в условиях сверхвысокого вакуума. Характеризация образцов выполнена in situ методами дифракции медленных электронов, фотоэлектронной спектроскопии высокого энергетического разрешения с использованием синхротронного излучения и магнитного линейного дихроизма в фотоэмиссии Со $3 p$ электронов. Получены новые данные об эволюции атомной, электронной структуры и магнитных свойств системы с увеличением толщины слоя интеркалированного кобальта в диапазоне до $2 \mathrm{~nm}$. Показано, что в ходе интеркаляции под слоем графена образуется псевдоморфная эпитаксиальная пленка $\mathrm{Co}(111)$, обладающая перпендикулярной поверхности намагниченностью в аномально широком диапазоне толщин.

Авторы признательны Helmholtz-Zentrum Berlin за возможность использования синхротронного излучения. И.И. Пронин благодарит Минобрнауки РФ за поддержку работы (задание 3.3161.2017 проектной части госзадания), Г.С. Гребенюк признателен РФФИ за финансовую поддержку (грант № 16-02-00387).

DOI: 10.21883/FTT.2017.10.44975.116

\section{1. Введение}

Благодаря уникальной электронной структуре, высокой подвижности носителей заряда и большой длине спиновой релаксации графен является перспективным материалом для микроэлектроники и спинтроники, который активно исследуется в последнее десятилетие $[1,2]$. Много внимания в этой связи уделяется проблемам роста и свойствам графена на металлических подложках, включая магнитные интерфейсы графен-железо и графен-кобальт. Проведенные исследования показали, что в этих системах имеет место сильное взаимодействие атомов углерода с подложкой, которое оказывает существенное влияние на электронные и магнитные свойства как графена, так и поверхности контактирующего с ним металла [3]. Причем эти свойства можно модифицировать путем интеркаляции (внедрения) различных элементов в межслоевой зазор между графеном и подложкой. Данный способ может быть также применен для формирования эпитаксиальных пленок железа [4-6] и кобальта [7-11], защищенных графеном от воздействия окружающей среды. Однако пленки кобальта в этих работах создавались лишь под графеном, сформированным на поверхности немагнитных металлов.
В настоящей работе мы впервые исследовали процесс интеркаляции кобальта под однослойный графен, выращенный на поверхности никеля. Целью исследования было выявить особенности атомной структуры, электронного строения и магнитных свойств образующихся пленок кобальта.

\section{2. Техника эксперимента}

Основные эксперименты проводили в РоссийскоГерманской лаборатории на синхротроне HZB BESSY II (г. Берлин). Они были выполнены в условиях сверхвысокого вакуума с использованием образцов монокристаллического вольфрама. На первой стадии эксперимента проводили очистку поверхности W(110). Для этого использовали чередующиеся отжиги образца в атмосфере кислорода (давление $1 \cdot 10^{-7} \mathrm{mbar}, 1100^{\circ} \mathrm{C}$ ) и в вакууме при $2000^{\circ} \mathrm{C}$. Далее на поверхности вольфрама формировали эпитаксиальные пленки $\mathrm{Ni}(111)$ толщиной $10 \mathrm{~nm}$. Напыление пленок никеля и кобальта осуществляли с помощью электронно-лучевых источников фирмы Omicron со скоростью $0.1 \mathrm{~nm} / \mathrm{min}$. На завершающей стадии подготовки образцов на поверхности никеля выращивали графен методом химического осаждения из газовой фазы. В качестве рабочего газа использовали 
пропилен (С3Н6). Крекинг пропилена проводили при давлении $2 \cdot 10^{-6} \mathrm{mbar}\left(600^{\circ} \mathrm{C}\right)$ в течение $10 \mathrm{~min}$. Такая процедура согласно, результатам работ [12,13], обеспечивает воспроизводимое формирование однослойного графена.

Интеркаляцию кобальта в межслоевой зазор между графеном и никелем осуществляли путем нанесения на поверхность образца сверхтонких пленок кобальта и последующего их отжига при $450^{\circ} \mathrm{C}$ в течение $10 \mathrm{~min}$. Количество нанесенного кобальта контролировали кварцевыми микровесами во время осаждения. Толщина нанесенных пленок варьировалась в диапазоне до $2 \mathrm{~nm}$. Анализ элементного и химического состава поверхности образцов, а также ее атомного строения проводили in situ методами фотоэлектронной спектроскопии (ФЭС) высокого энергетического разрешения и дифракции медленных электронов (ДМЭ). Энергия фотонов варьировалась в интервале $110-600 \mathrm{eV}$. Регистрацию спектров фотоэлектронов проводили с помощью сверхвысоковакуумного спектрометра с 200-миллиметровым полусферическим анализатором. Полное энергетическое разрешение прибора (включая разрешение монохроматора) составляло $100 \mathrm{meV}$. Этот же спектрометр применяли и для исследования магнитных свойств поверхности, которые анализировали с помощью эффекта магнитного линейного дихроизма (МЛД) в фотоэмиссии Со $3 p$ электронов. В ходе эксперимента исследуемые образцы облучали пучком линейно-поляризованного света под углом $30^{\circ}$ к поверхности. Эмитируемые фотоэлектроны регистрировали в конусе с полным раствором $10^{\circ}$, который был ориентирован вдоль нормали к поверхности образца. Вектор поляризации световой волны при этом лежал в горизонтальной плоскости фотоэмиссии. Намагничивание образцов проводили с помощью пары катушек Гельмгольца внутри вакуумной камеры. Пропусканием через них импульсов тока создавали вертикальное магнитное поле напряженностью 1000 Ое, параллельное поверхности образца. Регистрацию спектров проводили в режиме остаточной намагниченности при комнатной температуре и давлении остаточных газов $2 \cdot 10^{-10} \mathrm{mbar}$.

\section{3. Результаты и их обсуждение}

Картины ДМЭ, демонстрирующие достаточно высокое качество пленки никеля и графена, представлены на рис. 1. Первая из них (рис. 1,a) была получена после формирования на подложке при комнатной температуре пленки никеля толщиной $10 \mathrm{~nm}$. В ней отчетливо проявляются шесть дифракционных рефлексов, характерных для поверхности монокристалла $\mathrm{Ni}(111)$, обладающего ГЦК структурой. Эти рефлексы стали еще более четкими после формирования графена на поверхности образца, что позволило снизить энергию электронов при наблюдении картин ДМЭ со 131 до $94 \mathrm{eV}$ (рис. 1,b). Повышение яркости рефлексов и снижение интенсивности диффузного фона картины обусловлены преимуще-

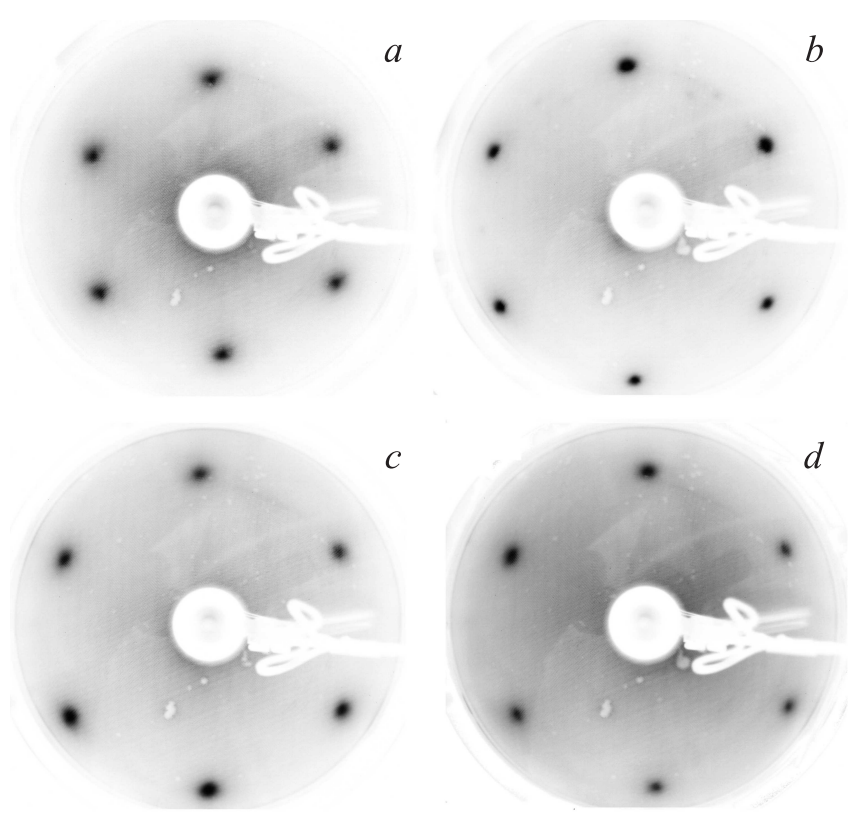

Рис. 1. Картины ДМЭ, полученные на разных стадиях формирования интеркаляционной системы графен-кобальт-никель. $a-\mathrm{Ni}(111) / \mathrm{W}(110), b-$ графен/Ni(111), $c-$ графен $/ 0.2 \mathrm{~nm}$ $\mathrm{Co} / \mathrm{Ni}(111), d-$ графен/2 nm $\mathrm{Co} / \mathrm{Ni}(111)$. Энергия электронов $131(a), 94 \mathrm{eV}(b-d)$.

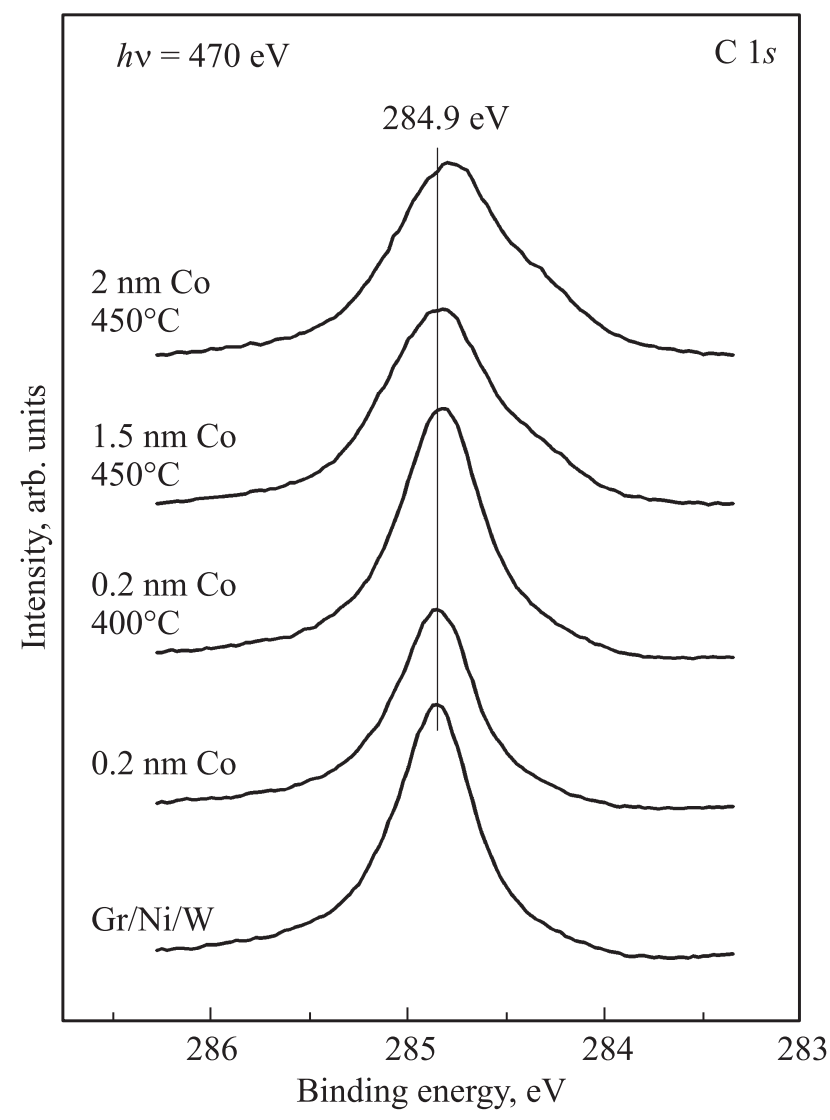

Рис. 2. Спектры ФЭС в области C $1 s$ электронов, измеренные после интеркаляции различных количеств кобальта (указаны в $\mathrm{nm}$ ) под слой графена, сформированный на пленке никеля. 


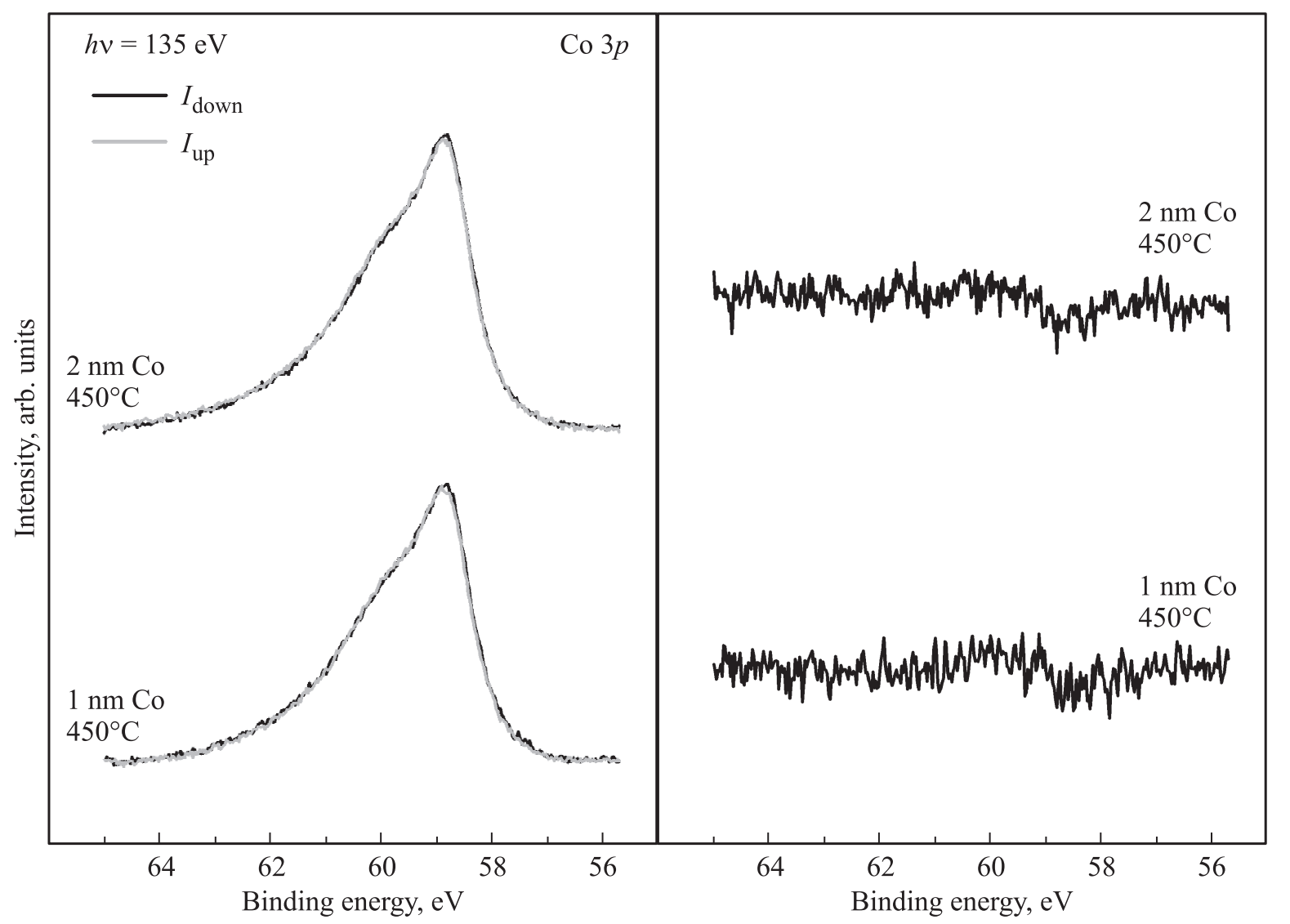

Рис. 3. Спектры фотовозбужденных Со $3 p$ электронов, измеренные для двух противоположных направлений намагниченности образца, интеркалированного различным количеством кобальта (1 и $2 \mathrm{~nm})$, и соответствующие этим спектрам разностные кривые.

ственно улучшением кристаллической структуры пленки никеля из-за ее отжига в процессе крекинга пропилена. Кроме того, заметный вклад в рефлексы дает и выращенный графен, двумерная решетка которого хорошо согласуется с решеткой поверхности никеля (различие постоянных решеток составляет лишь 1.3\%) и характеризуется картиной ДМЭ со структурой типа $(1 \times 1)$.

Информация о структуре графена и его связи с подложкой может быть получена из анализа формы линии фотоэмиссионного C $1 s$ спектра. Эволюция спектров С $1 s$ электронов с увеличением дозы интеркалированного кобальта иллюстрируется рис. 2. Исходный углеродный спектр, соответствующий графену на никеле, хорошо согласуется с литературными данными для системы $\mathrm{Gr} / \mathrm{Ni}(111)$ [4-6]. Он демонстрирует одиночную эмиссионную линию с энергией связи $284.9 \mathrm{eV}$, которая превышает аналогичную величину для графита примерно на $0.5 \mathrm{eV}$. Такая форма линии характерна для однослойного графена, атомы углерода которого сильно связаны с подложкой.

Нанесение на поверхность образца $0.2 \mathrm{~nm}$ Со при комнатной температуре приводит к заметному уменьшению интенсивности спектров С $1 s$ (рис. 2) и $\mathrm{Ni}$ $3 p$ электронов, но не меняет их формы линии, что свидетельствует об образовании на поверхности гра- фена островков кобальта. Отжиг системы при $400^{\circ} \mathrm{C}$, проведенный в течение $10 \mathrm{~min}$ вскоре после напыления Со, полностью восстанавливает интенсивность линии С $1 s$ до исходного уровня чистой поверхности графена (рис. 2), но не оказывает влияния на интенсивность сигнала от никелевой подложки. Последующие циклы аналогичных напылений и отжигов, проведенные в диапазоне толщин пленок кобальта до $2 \mathrm{~nm}$, дали сходные результаты и привели к тому, что интенсивность спектра C $1 s$ графена осталась неизменной, а линия $\mathrm{Ni} 3 p$, соответствующая подложке, полностью затухла.

Такое поведение спектров очень характерно для интеркаляционных систем [4]. Оно указывает на то, что атомы кобальта, нанесенные при комнатной температуре на поверхность графена, в ходе отжига образца проникают в межслоевой зазор между графеном и никелем. Механизм процесса интеркаляции основан на хорошо известном факте, состоящем в том, что графен, выращенный на поверхности таких переходных металлов, как $\mathrm{Ni}, \mathrm{Pt}$ и $\mathrm{Ru}$, обладает доменной структурой, а диффузия интеркалирующих элементов происходит по границам доменов [14]. Поскольку для частиц, осажденных на графене, диффузионный барьер является очень низким, атомы кобальта могут легко мигрировать к доменным границам и проникать через них под графен, постепен- 
но образуя пленку кобальта на никелевой подложке. Кристаллическое строение этой пленки из-за близости постоянных решеток контактирующих элементов воспроизводит ГЦК структуру $\mathrm{Ni}(111)$. Это хорошо видно из рис. $1, c, d$, который наглядно демонстрирует неизменность атомного строения интеркалированной пленки кобальта при увеличении ее толщины. Таким образом, полученные данные показывают, что использование процесса интеркаляции позволяет формировать под слоем графена эпитаксиальные пленки кобальта толщиной до $2 \mathrm{~nm}$.

Рассмотрим теперь результаты исследования магнитных свойств системы, полученные с помощью эффекта МЛД. Как известно, эффект проявляется в зависимости формы линии фотовозбужденных линейнополяризованным светом остовных электронов от направления намагниченности образца в плоскости поверхности [15-18]. Причиной его возникновения является энергетическое расщепление возбуждаемого спинорбитального дублета на подуровни с различными магнитными квантовыми числами, обусловленное взаимодействием остовного уровня с магнито-поляризованной валентной зоной.

Типичные спектры Co $3 p$ электронов, полученные для пленок интеркалированного кобальта толщиной 1 и $2 \mathrm{~nm}$, показаны в левой части рис. 3. В каждом случае они измерялись для двух противоположных направлений намагниченности образца $\left(M_{\text {up }}\right.$ и $\left.M_{\text {down }}\right)$. Из рисунка видно, что для обеих пленок спектры $I_{\text {up }}$ и $I_{\text {down }}$ практически ничем не отличаются друг от друга. Для того чтобы более наглядно продемонстрировать отсутствие эффекта МЛД в данной системе, в правой части рис. 3 представлены разностные кривые $I_{\text {up }}-I_{\text {down }}$, которые позволяют более детально выявить различия анализируемых спектров. Однако и они демонстрируют лишь некоторый шум в окрестности линии Со $3 p$. Все это говорит об отсутствии ферромагнитного упорядочения пленок интеркалированного кобальта вдоль поверхности.

Полученный результат оказался весьма неожиданным, поскольку ранее мы неоднократно наблюдали эффект МЛД для пленок кобальта, сформированных на разных гранях кремния [19-21], вольфрама [22] и железа [23]. Эффект всегда носил пороговый характер и обнаруживался после нанесения на подложку примерно 0.6 nm Co. Причиной его возникновения является хорошо известное свойство сверхтонких магнитных пленок менять ориентацию вектора намагниченности с увеличением толщины (Spin reorientation transition) [24]. Оно проявляется в том, что для самых тонких пленок этот вектор обычно перпендикулярен поверхности, а при увеличении их толщины он поворачивается к поверхности, и в этот момент как раз и появляется эффект МЛД. Таким образом, полученные результаты свидетельствуют о том, что интеркалированные пленки кобальта обладают перпендикулярной намагниченностью в необычно большом диапазоне толщин, по крайней мере, до $2 \mathrm{~nm}$ Co.
Аномальное поведение рассматриваемой системы может быть обусловлено спецификой строения сформированных пленок кобальта на никеле и/или влиянием на магнитные свойства пленок покрывающего их графена. Веским аргументом в пользу последнего фактора являются результаты работы [25], авторы которой исследовали магнитные свойства интеркаляционной системы графенкобальт-иридий. Они обнаружили, что размерная зависимость эффекта периориентации спина для данной системы является чрезвычайно затянутой и протекает в аномально широком диапазоне толщин пленок кобальта (от 12 до 24 монослоев). Сходный, но значительно менее выраженный эффект влияния графена на магнитные свойства интеркалированной пленки железа недавно наблюдался и для системы графен-железо-никель [26].

\section{4. Заключение}

Применение комплекса методов электронной спектроскопии и дифракции к исследованию интеркаляционной системы графен-кобальт-никель показало, что кобальт, проникающий в межслойный зазор между графеном и никелем при $400-450^{\circ} \mathrm{C}$, образует певдоморфные эпитаксиальные пленки $\operatorname{Co}(111)$, обладающие ГЦК структурой. Таким способом можно формировать под графеном пленки кобальта нанометровой толщины. Эти пленки обладают перпендикулярной намагниченностью в необычно большом диапазоне толщин, по крайней мере, до $2 \mathrm{~nm} \mathrm{Co.}$

\section{Список литературы}

[1] A.K. Geim, K.S. Novoselov. Nature Mater. 6, 183 (2007).

[2] J. Wintterlin, M.-L. Bocquet. Surf. Sci. 603, 1841 (2009).

[3] Yu. Dedkov, E. Voloshina. J. Phys.: Condens. Mater. 27, 303002 (2015).

[4] Yu.S. Dedkov, M. Fonin, U. Rüdiger C. Laubschat. Appl. Phys. Lett. 93, 022509 (2008).

[5] M. Weser, E.N. Voloshina, K. Horn, Y.S. Dedkov. Phys. Chem. Chem. Phys. 13, 7534 (2011).

[6] E.A. Soares, G.J.P. Abreu, S.S. Carara, R. Paniago, V.E. de Carvalho, H. Chacham. Phys. Rev. B 88, 165410 (2013).

[7] S. Vlaic, A. Kimouche, J. Coraux, B. Santos, A. Locatelli, N. Rougemaille. Appl. Phys. Lett. 104, 10, 101602 (2014).

[8] R. Decker, J. Brede, N. Atodiresei, V. Caciuc, S. Blugel, R. Wiesendanger. Phys. Rev. B 87, 041403 (2013).

[9] H. Vita, S. Bottcher, P. Leicht, K. Horn, A.B. Shick, F. Maca. Phys. Rev. B 90, 165432 (2014).

[10] D. Pacile, S. Lisi, I. Di Bernardo, M. Papagno, L. Ferrari, M. Pisarra, M. Caputo, S.K. Mahatha, P.M. Sheverdyaeva, P. Moras, P. Lacovig, S. Lizzit, A. Baraldi, M.G. Betti, C. Carbone. Phys. Rev. B 90, 195446 (2014).

[11] J. Drnec, S. Vlaic, I. Carlomagno, C.J. Gonzalez, H. Isern, F. Carla, R. Fiala, N. Rougemaille, J. Coraux, R. Felici. Carbon 94, 554 (2015).

[12] A. Grüneis, K. Kummer, D.V. Vyalikh. New J. Phys. 11, 073050 (2009).

[13] A. Varykhalov, O. Rader. Phys. Rev. B 80, 035437 (2009). 
[14] А.Я. Тонтегоде, Е.В. Рутьков. УФН 163, 11, 57 (1993).

[15] Ch. Roth, F.U. Hillebrecht, H.B. Rose, E. Kisker. Phys. Rev. Lett. 70, 3479 (1993).

[16] F. Sirotti, G. Rossi. Phys. Rev. B 49, 15682 (1994).

[17] N. Janke-Gilman, M. Hochstrasser, R.F. Willis. Phys. Rev. B 70, 184439 (2004).

[18] I.I. Pronin, M.V. Gomoyunova, D.E. Malygin, D.V. Vyalikh, Yu.S. Dedkov, S.L. Molodtsov. J. Appl. Phys. 104, 104914 (2008).

[19] И.И. Пронин, М.В. Гомоюнова, С.М. Соловьев, О.Ю. Вилков, Д.В. Вялых. ФТТ 53, 573 (2011).

[20] М.В. Гомоюнова, Г.С. Гребенюк, И.И. Пронин. ЖТФ 81, 6 , 120 (2011).

[21] М.В. Гомоюнова, Г.С. Гребенюк, К.М. Попов, И.И. Пронин. ЖТФ 83, 6, 78 (2013).

[22] Г.С. Гребенюк, М.В. Гомоюнова, О.Ю. Вилков, Б.В. Сеньковский, И.И. Пронин. ФТТ 58, 2059 (2016).

[23] М.В. Гомоюнова, Г.С. Гребенюк, И.И. Пронин. ЖТФ 84, 10,73 (2014).

[24] J.-W. Lee, J.-R. Jeong, S.-C. Shin, J. Kim. S.-K. Kim. Phys. Rev. B 66, 172409 (2002).

[25] A.D. Vu, J. Coraux, G. Chen, A.T. N'Diaye, A.K. Schmid, N. Rougemaille. Sci. Reports 6, 24783 (2016).

[26] G.S. Grebenyuk, O.Yu. Vilkov, A.G. Rybkin, M.V. Gomoyunova, B.V. Senkovskiy, D.Yu. Usachov, D.V. Vyalikh, S.L. Molodtsov, I.I. Pronin. Appl. Surf. Sci. 392, 715 (2017). 